\title{
Balai Pembinaan Dan Pelatihan \\ KETERAMPILAN ANAK JALANAN \\ Dengan Pendekatan Fleksibilitas Arsitektur \\ Di SURAKARTA
}

\author{
Gigih Herry P, Musyawaroh, Maya Andria N. \\ Program Studi Arsitektur \\ Fakultas Teknik \\ Universitas Sebelas Maret Surakarta \\ Email : gigihherrypurwoko@gmail.com
}

\begin{abstract}
Surakarta city as a big city in Central Java, which continues to grow can not be separated from the phenomenon of street children problem. As a city that wants to be a childfriendly city, the phenomenon of street children in the city is less serious attention to the lack of street children buildings or vocational training for the street children. For it is necessary to design a building that is capable of being marcusuar in the overcome of street children problem in the city. Architectural flexibility is the tendency of architectural objects to be changed, both in shape, size and structure, with the aim of being able to adjust to the needs of users, making it more effective and efficient. The method used is the method of approach architecture with the flexibility of the architecture. The result obtained is a design of a building that is destined for coaching for the psychological rehabilitation as well as a place for the vocational training for the street children in Surakarta, which could accommodate the needs of users in an effective and efficient approach architectural flexibility.
\end{abstract}

Keywords: Architectural flexibility, Street children, Vocational training,

\section{PENDAHULUAN}

Sebagai salah satu kota besar di Jawa Tengah yang mengalami perkembangan yang relatif pesat, Kota Surakarta tidak lepas dari problematika anak jalanan. Jumlah anak jalanan di Kota Surakarta terus mengalami peningkatan setiap tahunnya. Pertambahan jumlah anak jalanan ini bukan hanya berasal dari dalam Kota Surakarta, namun juga berasal dari kota-kota lain di sekitarnya. Dalam lima tahun terakhir (2010-2015) jumlah anak jalanan telah peningkat secara pesat mencapai lebih dari $300 \%$. Diperkirakan jumlah tersebut akan terus meningkat jika tidak ada penanganan yang jelas dan nyata dari pihakpihak terkait. Hal tersebut merupakan fenomena sosial yang harus mendapatkan perhatian secara serius guna merumuskan penyelesaiannya sesegera mungkin.

Pertambahan jumlah anak jalanan tersebut belum mendapat perhatian yang serius dari pihak-pihak terkait seperti pemerintah dan dinas sosial dengan belum adanya fasilitas untuk penanggulangan anak jalanan yang tersedia di kota ini, sedangkan di sisi lain Kota
Surakarta tengah mencanangkan untuk dapat menjadi Kota Layak Anak. Kota Surakarta belum memiliki fasilitas bangunan yang digunakan untuk penanggulangan anak jalanan. Bahkan belum memiliki rumah singgah untuk anak jalanan yang terintegrasi dengan Dinas Sosial Kota Surakarta. Meskipun sudah ada usaha dari berbagai pihak yang peduli akan hal ini, namun usaha yang dilakukan dengan membangun rumah singgah anak jalanan juga belum optimal.

Penanggulangan anak jalanan merupakan suatu upaya yang harus dilakukan secara komprehensif dan terintegrasi antara pihak-pihak terkait, baik itu dinas sosial, LSM, yayasan peduli anak jalanan, maupun keluarga dan lingkungan sosial anak. Perlu adanya kerjasama dari berbagai pihak untuk dapat mengatasi masalah anak jalanan ini. Menurut Sudrajat (1996), ada tiga model yang dapat dilakukan untuk mengatasi anak jalanan, yaitu street based (turun ke jalan), centre based (terpusat), dan community based (melibatkan komunitas dan keluarga). Dengan adanya 
usaha penanggulangan yang terintegrasi, maka tingkat keberhasilannya akan lebih tinggi.

Berdasarkan hal-hal tersebut, maka Kota Surakarta membutuhkan suatu wadah untuk penanggulangan masalah anak jalanan berupa balai untuk perlindungan, pembinaan dan pelatihan keterampilan terhadap anak jalanan untuk bekal mencari nafkah dengan layak tanpa harus menjadi anak jalanan.

Dalam hal perancangan bangunan, anakanak jalanan ini butuh tempat yang membuat mereka merasa nyaman, tidak mengekang, tidak statis dan dapat menyesuaikan dengan keadaan sosial mereka. Untuk itu dalam perancangan pusat pembinaan dan pelatihan keterampilan anak jalanan di Kota Surakarta ini dipilih pendekatan Fleksibilitas Arsitektur. Bangunan yang direncanakan juga harus mampu merepresentasikan fungsinya yaitu sebagai bangunan untuk anak jalanan.

\section{METODE}

Metode yang digunakan dalam perencanaan dan perancangan balai pembinaan dan pelatihan anak jalanan ini adalah metode arsitektur dengan pendekatan Fleksibilitas Arsitektur. Konsep Fleksibilitas Arsitektur yang digunakan menggunakan konsep fleksibilitas menurut Hill (2003), yaitu flexibility by technical means, flexibility by open plan dan flexibility by spatial redundancy.

Cara Fleksibilitas Arsitektur diterapkan ke dalam desain balai pembinaan dan pelatihan keterampilan anak jalanan ini adalah sebagai berikut:

A. Penggunaan sekat/partisi yang tidak permanen.

Hal ini adalah penerapan konsep flexibility by technical means, yaitu dengan pemberian perlakuan yang berbeda pada ruang kelas dan pelatihan dengan pemberian dinding lipat maupun dinding geser untuk membagi ruang menjadi beberapa ruang yang lebih kecil sehingga dapat menyesuaikan dengan kebutuhan.

B. Penerapan tata letak ruang dengan open plan.

Hal ini merupakan penerapan konsep flexibility by open plan, yaitu dengan penataan ruang-ruang yang saling berhubungaan sehingga apabila dibutuhkan penggantian, penggabungan ataupun pemisahan fungsi ruang dapat dilakukan dengan cepat.

C. Penggubahan ruang dengan fungsi umum. Hal ini merupakan penerapan dari konsep flexibility by spatial redurancy yaitu dengan penciptaan ruang-ruang yang berukuran besar dan memiliki fungsi umum, sehingga dapat digunakan untuk berbagai hal.

\section{ANALISIS}

A. Analisis Peruangan

Pada analisis peruangan dilakukan analisis mengenai pengguna bangunan dan macam kegiatan dari setiap pengguna untuk mendapatkan kebutuhan ruang.

Tabel 1.Kebutuhan Ruang

\begin{tabular}{|l|l|l|}
\hline PELAKU & KEGIATAN & PERUANGAN \\
\hline \multirow{3}{*}{$\begin{array}{l}\text { Anak } \\
\text { jalanan }\end{array}$} & Tidur/tinggal & Asrama \\
\cline { 2 - 3 } & Belajar & R. Kelas \\
\cline { 2 - 3 } & Pelatihan & Workshop \\
\cline { 2 - 3 } & Olah raga & Lapangan \\
\cline { 2 - 3 } & Ibadah & Masjid \\
\hline Pengunjung & Datang & Hall penerima \\
\cline { 2 - 3 } & $\begin{array}{l}\text { Membeli } \\
\text { produk }\end{array}$ & Outlet produk \\
\cline { 2 - 3 } & $\begin{array}{l}\text { Mencari } \\
\text { tenaga kerja }\end{array}$ & $\begin{array}{l}\text { R. Penyaluran } \\
\text { tenaga kerja }\end{array}$ \\
\hline Pengelola & Pengelolaan & Kantor \\
\hline
\end{tabular}

Pada Tabel 1. terlihat kebutuhan peruangan utama yang dibutuhkan dalam pemenuhan wadah pembinaan dan pelatihan keterampilan.

\section{B. Analisis Lokasi}

Selain menentukan lokasi yang dekat dengan tempat-tempat berkumpulnya anak jalanan, memilih tapak yang strategis dengan kondisi yang mendukung keberadaan balai pembinaan dan pelatihan keterampilan anak jalanan ini sangat menentukan prospek bangunan tersebut.

\section{Tujuan}

Mendapatkan lokasi yang sesuai untuk balai pembinaan dan pelatihan keterampilan anak jalanan. 
2. Dasar pertimbangan

Posisi tapak dekat dengan tempattempat berkumpul anak jalanan dan strategis untuk pemasaran produk, luasan tapak dapat menampung seluruh kebutuhan ruang yang direncanakan.

\section{Analisis Pencapaian}

Pencapaian ke dalam bangunan harus mudah diakses, mudah dilihat dan memiliki sirkulasi yang aman akan menstimulus orang untuk masuk dalam area bangunan.

1. Tujuan: menentukan main entrance masuk, main entrance ke luar dan menentukan service entrance

2. Dasar Pertimbangan: kemudahan akses, sirkulasi tapak yang aksesibel, arus kendaraan dan potensi jalan, tingkat keamanan.

3. Proses analisis

Main Entrance (ME)

Mudah dijangkau dan terlihat dengan jelas. Menghadap langsung ke arah jalan utama untuk kemudahan sirkulasi kendaraan masuk dan ke luar tapak.

Side Entrance (SE)

Tidak mengganggu keberadaan ME. Membantu sirkulasi pengunjung (lihat Gambar 1).

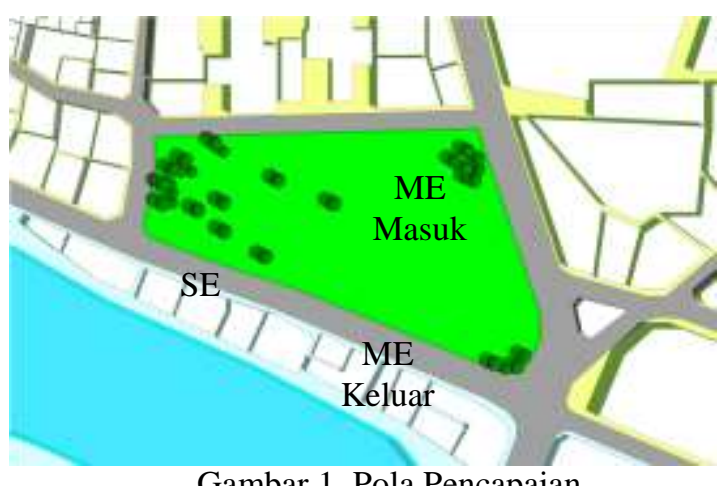

Gambar 1. Pola Pencapaian

D. Analisis Pemintakatan (Penzoningan)

Pemintakatan berdasarkan sifat kegiatan dan keadaan dalam tapak dilakukan sebagai acuan dalam penataan peruangan.

1. Tujuan: Menentukan mintakat (zoning) berdasarkan sifat kegiatan dan keadaan pada tapak.
2. Dasar pertimbangan: analisis peruangan, analisis pengolahan tapak.

3. Proses analisis: persyaratan ruang, berdasarkan kelompok kegiatan dan analisis pengolahan tapak.

Tabel 2. Persyaratan Ruang

\begin{tabular}{|l|l|l|}
\hline \multicolumn{1}{|c|}{$\begin{array}{l}\text { MINTA } \\
\text { KAT }\end{array}$} & KEL. RUANG & \multicolumn{1}{|c|}{ PERSYARATA } \\
\hline Publik & $\begin{array}{l}\text { Penerima, } \\
\text { Outlet } \text { produk }\end{array}$ & $\begin{array}{l}\text { Pencapaian mudah } \\
\text { View from/to site } \\
\text { menjadi } \\
\text { pertimbangan utama } \\
\text { Pencahayaan dan } \\
\text { penghawaan alami } \\
\text { penting }\end{array}$ \\
\hline $\begin{array}{l}\text { Semi } \\
\text { publik }\end{array}$ & $\begin{array}{l}\text { Workshop, } \\
\text { kelas, masjid, } \\
\text { pengelola }\end{array}$ & $\begin{array}{l}\text { Pencapaian telihat, } \\
\text { noise penting } \\
\text { Pencahayaan dan } \\
\text { penghawaan alami. }\end{array}$ \\
\hline Privat & Asrama & $\begin{array}{l}\text { Pencapaian tertutup, } \\
\text { pencahayaan dan } \\
\text { penghawaan alami, } \\
\text { noise dimimalkan, } \\
\text { view penting. }\end{array}$ \\
\hline
\end{tabular}

Pada Tabel 2. terlihat kebutuhan persyaratan peruangan yang dikelompokkan berdasarkan hierarki pemintakatan ruang.

E. Analisis Bentuk dan Tampilan Bangunan

1. Analisis Bentuk Bangunan

Massa bangunan ditata secara linear yang melingkar sehingga memberi kesan melingkupi lapangan dan komunal yang diletakkan di tengah tapak. Orientasi massa bangunan kelas, asrama dan servis menghadap ke arah dalam, sedangkan orientasi bangunan kantor dan workshop memiliki orientasi ganda, yaitu ke dalam dan ke luar tapak (lihat Gambar 2). 


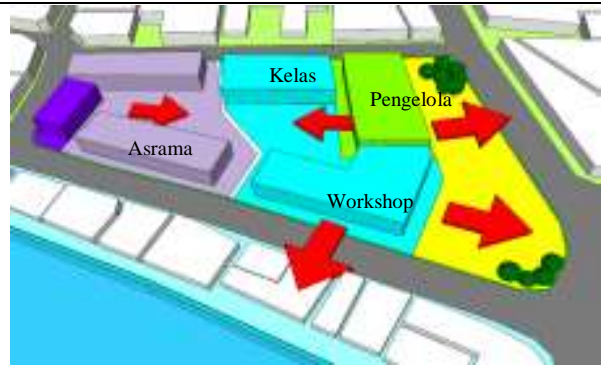

Gambar 2. Penataan Massa Bangunan

2. Analisis Bentuk dan Tata Letak

Ruang

Bertujuan menentukan konsep bentuk ruang serta penataan dari elemen interior yang menyertai ruang tersebut. Elemen interior yang dibahas di sini adalah perabot dan tata letaknya. Ruang yang dirancang diharapkan memiliki fungsi yang umum, dan dapat berubah fungsi sesuai dengan kebutuhan pengguna. Untuk dapat memiliki fleksibilitas fungsi ini, perlu adanya transformasi bentuk, ukuran, dan Tata letak ruang. Transformasi bentuk dan ukuran ruang dapat dilakukan dengan penerapan transformable wall seperti sliding wall, movable wall, folded wall, dan lain-lain (lihat Gambar 3).

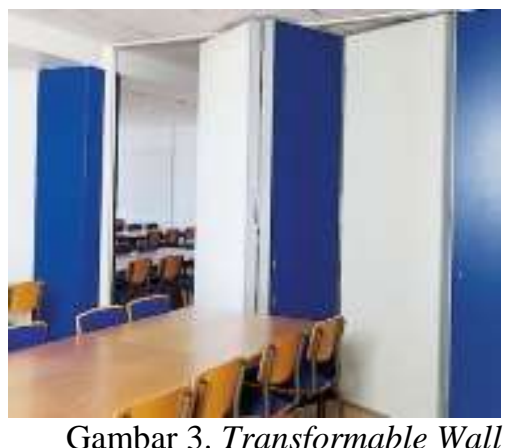

Kemudian perubahan bentuk ruang ini bisa didukung dengan konsep adaptable layout. Tata letak perabot yang ada pada ruangan sebisa mungkin dapat berubah menyesuaikan dengan fungsi yang dibutuhkan (lihat Gambar 4). Alternatif perabot yang digunakan harus mudah dipindah dan bisa juga menggunakan perabot

moduler.
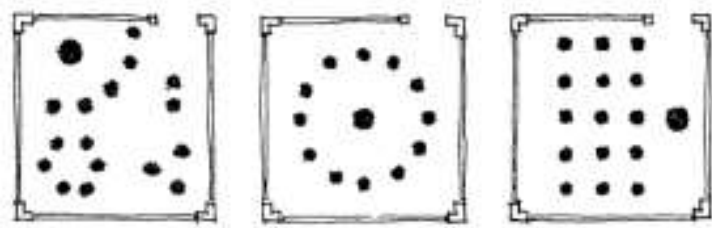

Gambar 4. Adaptable layout

3. Analisis Tampilan Bangunan Tampilan bangunan menggunakan facade dari material-material lokal yang efisien dan mampu merepresentasikan kesederhanaan anak jalanan, antara lain kayu, bambu, batu alam, batu bata ekspose, dinding tanaman, dan lainlain yang sejenis. Kemudian alternatif warna yang digunakan pada facade adalah warna-warna alam yang lembut dan menenangkan. Selain itu facade bangunan juga menggunakan kotak kontainer untuk merepresentasikan asal dari anak jalanan (lihat Gambar 5).

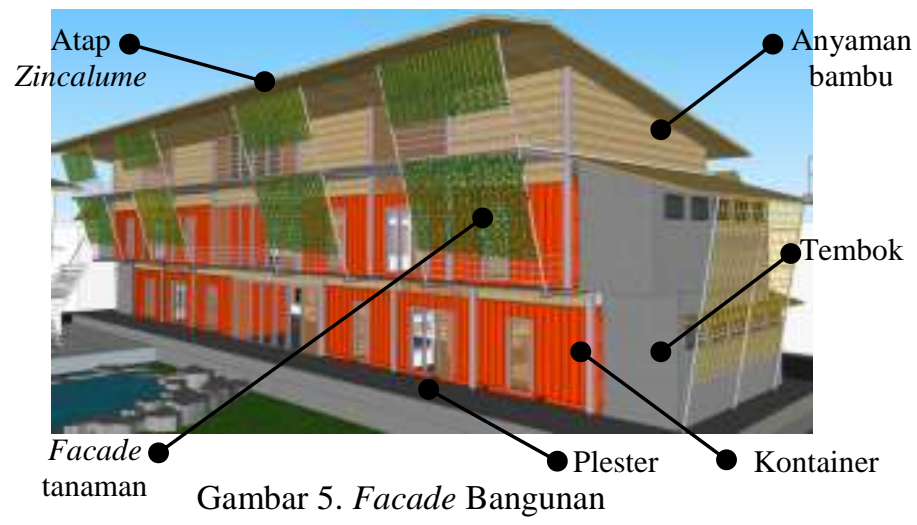

F. Analisis Material dan Struktur

Bangunan

1. Analisis Material Bangunan

Tujuan: menentukan konsep material yang sesuai dengan struktur, tampilan, dan karakter ruang yang ingin dihasilkan.

Material yang digunakan untuk bangunan menggunakan material yang low-cost. Materal yang digunakan pada dinding bangunan 
antara lain kotak kontainer, batu bata, kayu dan bambu.

Material lantai yang digunakan yaitu lantai dari plester beton, lantai kayu dan juga lantai keramik untuk bagian interior. Sedangkan pada eksterior menggunakan grass-block untuk area yang membutuhkan perkerasan.

Material atap yang digunakan secara umum yaitu menggunakan atap bambu belah yang disusun sedemikian rupa dan telah diawetkan dengan direndam pada air garam dan dilumuri cairan khusus. Selain itu juga menggunakan atap zincalume (lihat Gambar 5).

2. Analisis Struktur Bangunan

Tujuan: menentukan konsep struktur yang tepat untuk bangunan yang mampu menunjang penerapan konsep Fleksibilitas Arsitektur.

Dasar pertimbangan: kesesuaian dengan daya dukung tanah, kemudahan pemasangan saat konstruksi, bentuk massa bangunan, kekuatan dalam mendukung beban bangunan, estetika struktur dan kesesuaian dengan konsep tampilan bangunan, efektif dan efisien, kesesuaian dengan konsep Fleksibilitas Arsitektur.

a. Sub structure pada bangunan yang direncanakan menggunakan pondasi titik berupa footplate untuk menopang struktur rangka baja. Kemudian menggunakan pondasi batu kali pada bangunan dengan struktur beton bertulang. Pada struktur kontainer hanya dilakukan pembautan agar tidak bergeser (lihat Gambar 6, 7).

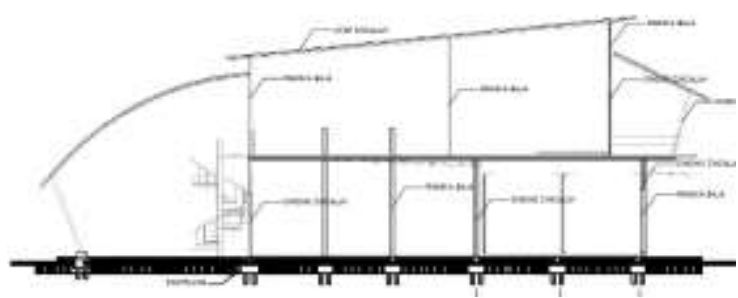

Gambar 6. Struktur Bangunan

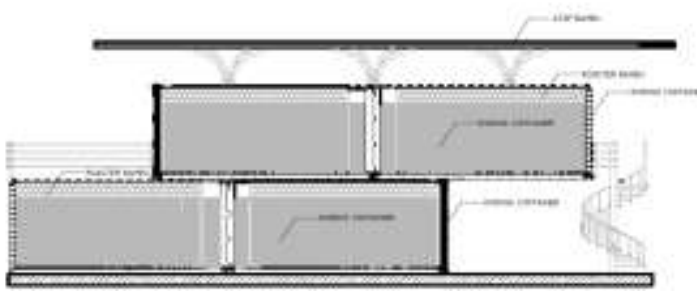

Gambar 7. Struktur Bangunan Kontainer

b. Super Structure menggunakan struktur rangka baja (rigid) yang dapat dikombinasi sehingga mampu menciptakan bangunan yang kokoh menahan beban di dalamnya juga menarik (bernilai estetika) serta dapat sesuai dengan konsep Fleksibilitas Arsitektur yang direncanakan (lihat Gambar 6).

Pada bagian bangunan dengan kotak kontainer tetap mempertahan struktur rangka kontainer (lihat Gambar 7).

c. Upper Structure menggunakan sistem struktur rangka baja dan kayu yang mudah diaplikasikan pada bangunan serta lebih ekonomis (lihat Gambar 6, 7).

\section{KESIMPULAN (KONSEP DESAIN)}

Konsep rancangan balai pembinaan dan pelatihan keterampilan anak jalanan mengacu pada pemenuhan kebutuhan ruang pengguna secara efektif dan efisien dengan penerapan Fleksibilitas Arsitektur. Fleksibilitas Arsitektur juga berperan dalam penciptaan ruang yang tidak statis dan monoton yang terasa mengekang kebebasan anak. Selain itu bangunan juga berfungsi sebagai penyalur tenaga kerja serta pasar untuk penjualan 
produk-produk yang dihasilkan oleh anak jalanan.

Dari hasil analisis serta hasil korelasi dari beberapa data di atas, maka diperoleh hasil berupa rancangan Balai Pembinaan dan Pelatihan Keterampilan Anak Jalanan di Surakarta sebagai berikut.
Nama Balai : Rumah Kolong Langit
Lokasi : Jl. Kapten Pierre Tendean
Luas Lahan $\quad: 9.450 \mathrm{~m}^{2}$
Luas Bangunan : $5700 \mathrm{~m}^{2}$
Daya Tampung : 160 anak
Kegiatan : Pembinaan dan pelatihan
Keterampilan anak jalanan

Efektivitas dan efisiensi penggunaan tapak dioptimalkan dengan memaksimalkan luasan bangunan pada tapak yang terbatas (lihat Lampiran 1). Massa bangunan ditata secara linier melingkar agar terkesan melingkupi (lihat Gambar 8).

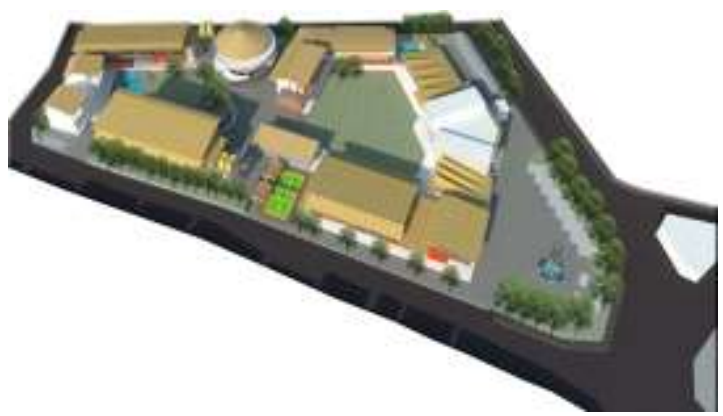

Gambar 8. Perspektif Eksterior

Penghawaan dan pencahayaan alami ke bangunan diptimalkan untuk kenyamanan pengguna dan efisiensi energi serta biaya (lihat Gambar 9).

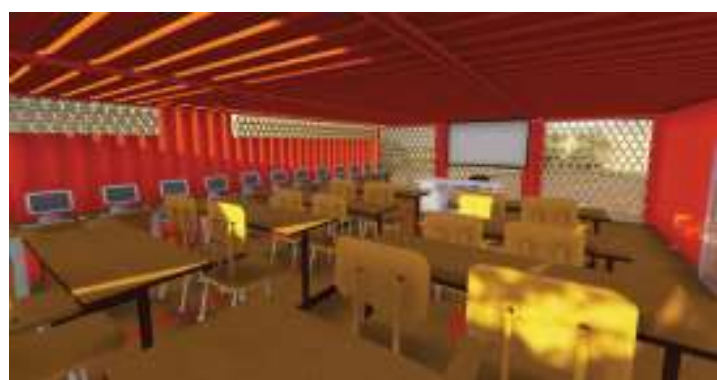

Gambar 9. Gambar interior

\section{REFERENSI}

Hill, Jonathan. 1998, Occupying Architecture :
Between the Architect and the User.

Sudrajat, Tata.1996, Anak Jalanan dan Masalah Sehari-hari sampai Kebijaksanaan. 
LAMPIRAN

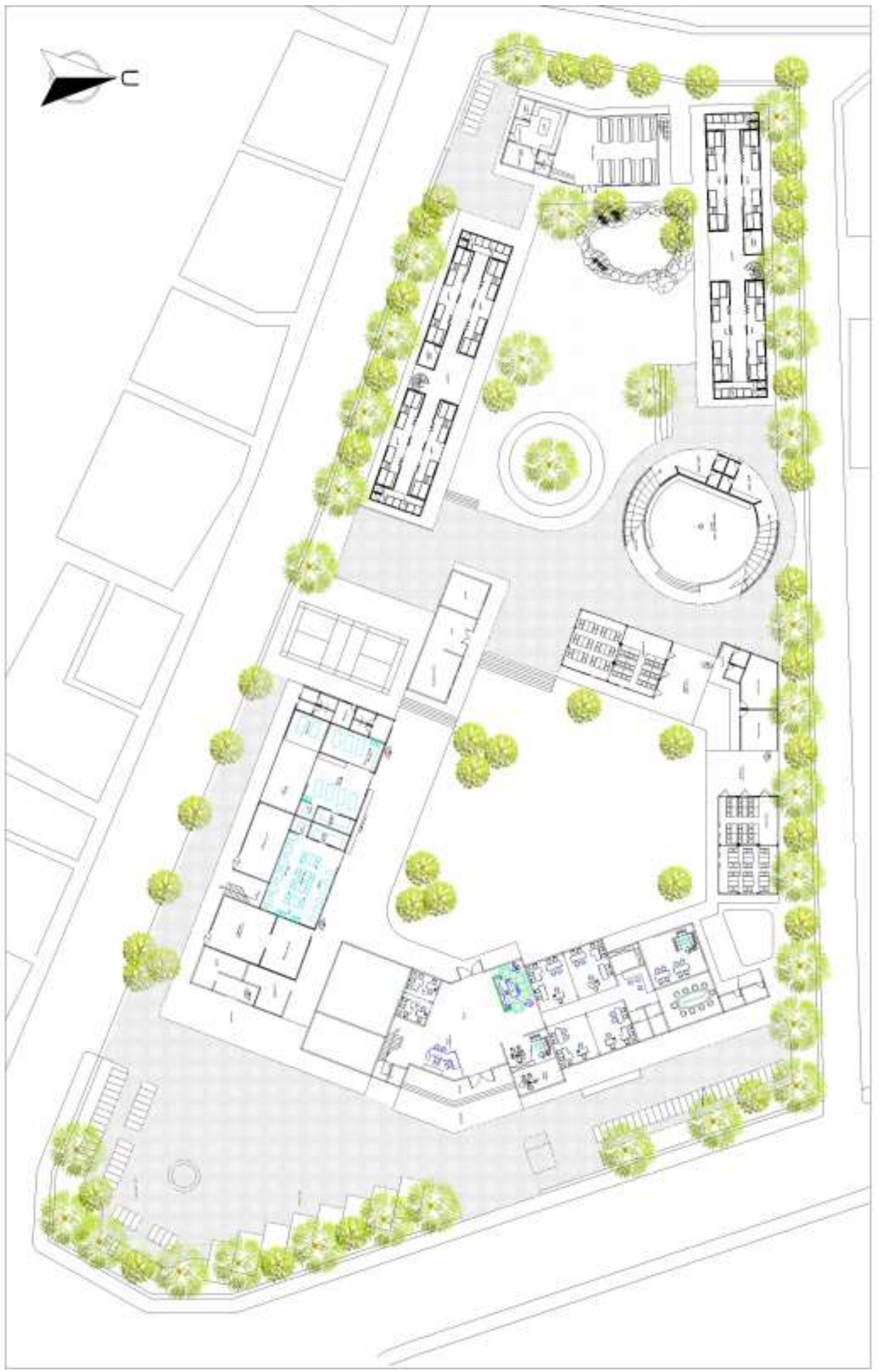

Lampiran 1. Rencana Tapak 